\title{
Correction to: Increased Levels of Plasma Tumor Necrosis Factor-a Mediate Schizophrenia Symptom Dimensions and Neurocognitive Impairments and Are Inversely Associated with Natural IgM Directed to Malondialdehyde and Paraoxonase 1 Activity
}

\author{
Michael Maes ${ }^{1,2,3}$. Sunee Sirivichayakul ${ }^{4}$. Andressa Keiko Matsumoto ${ }^{5} \cdot$ Annabel Maes $^{6} \cdot$ Ana Paula Michelin $^{5}$. \\ Laura de Oliveira Semeão ${ }^{5}$. João Victor de Lima Pedrão ${ }^{5}$. Estefania G.Moreira ${ }^{5}$. Decio S. Barbosa ${ }^{5}$. \\ Michel Geffard ${ }^{7}$. Andre F. Carvalho ${ }^{8}$. Buranee Kanchanatawan ${ }^{1}$
}

Published online: 18 January 2022

(c) Springer Science+Business Media, LLC, part of Springer Nature 2022

Correction to: Molecular Neurobiology (2020) 57:2333-2345

https://doi.org/10.1007/s12035-020-01882-w

In this article the affiliation details for Author 'Annabel Publisher's Note Springer Nature remains neutral with regard to jurisdictional claims in published maps and institutional affiliations. Maes' were incorrectly given as ' Johnson and Johnson, Beerse, Belgium' but should have been 'Kiezelweg 108, 3620 Lanaken, Belgium'.

The original article can be found online at https://doi.org/10.1007/ s12035-020-01882-w

Andre F. Carvalho

andre.carvalho@camh.ca; andrefc7@hotmail.com

Michael Maes

dr.michaelmaes@hotmail.com

Sunee Sirivichayakul

Sunee.S@chula.ac.th

Andressa Keiko Matsumoto

dessamatsu@hotmail.com

Annabel Maes

annabel.maes@outlook.com

Ana Paula Michelin

paulimichelin10@gmail.com

Laura de Oliveira Semeão

1semeao@gmail.com

João Victor de Lima Pedrão

jvpedrao@gmail.com

Estefania G.Moreira

egmoreira22@hotmail.com

Decio S. Barbosa

sabbatini2011@ @otmail.com

Michel Geffard

idrpht@wanadoo.fr
Buranee Kanchanatawan

drburanee@gmail.com

1 Department of Psychiatry, Faculty of Medicine, Chulalongkorn University, Bangkok, Thailand

2 Department of Psychiatry, Medical University of Plovdiv, Plovdiv, Bulgaria

3 IMPACT Strategic Research Center, Deakin University, Geelong, Australia

4 Department of Medicine, Faculty of Medicine, Chulalongkorn University, Bangkok, Thailand

5 Health Sciences Graduate Program, Health Sciences Center, State University of Londrina, Londrina, PR, Brazil

6 Kiezelweg 108, 3620 Lanaken, Belgium

7 Research Department, IDRPHT, Talence, France

8 Department of Psychiatry, University of Toronto and Centre for Addiction and Mental Health (CAMH), Bell Gateway Building, 100 Stokes Street, 4th Floor, Toronto, ON M6J 1H4, Canada 